\title{
Leisure-time physical activity and nutrition: a twin study
}

\author{
Mirva Rintala ${ }^{1, *}$, Arja Lyytikäinen ${ }^{1,2}$, Tuija Leskinen ${ }^{1}$, Markku Alen ${ }^{3}$, \\ Kirsi H Pietiläinen ${ }^{4}$, Jaakko Kaprio ${ }^{5,6,7}$ and Urho M Kujala ${ }^{1}$ \\ 'Department of Health Sciences, University of Jyväskylä, PO Box 35(LL), FIN-40014 University of Jyväskylä, \\ Finland: ${ }^{2}$ Unit of Family Practice, Central Finland Health Care District, Jyväskylä, Finland: ${ }^{3}$ Department of \\ Medical Rehabilitation, Oulu University Hospital, and University of Oulu, Oulu, Finland: ${ }^{4}$ Obesity Research Unit, \\ Biomedicum Helsinki, Helsinki University Central Hospital, Helsinki, Finland: ${ }^{5}$ Department of Public Health, \\ University of Helsinki, Helsinki, Finland: ${ }^{6}$ Institute for Molecular Medicine FIMM, Helsinki, Finland: ${ }^{7}$ National \\ Institute for Health and Welfare, Helsinki, Finland
}

Submitted 2 December 2009: Accepted 17 March 2010: First published online 4 May 2010

\begin{abstract}
Objective: To determine the association between long-term leisure-time physical activity/inactivity and eating behaviours in twin pairs discordant for physical activity for 30 years.

Design: Co-twin control design with cross-sectional data collection using questionnaire on eating habits and $5 \mathrm{~d}$ food diary. Differences in eating behaviours between physically active and inactive co-twins were analysed with pairwise tests. Setting: Finland.

Subjects: Sixteen same-sex twin pairs (seven monozygotic and nine dizygotic, mean age 60 years) discordant for physical activity, selected from the Finnish Twin Cohort on the basis of physical activity discordance for 30 years, blinded to their possible differences in eating behaviours.

Results: The eating habits questionnaire revealed that physically active co-twins more frequently reported that it is easy to eat according to need, whereas overeating and/ or restrictive eating was more common among the inactive co-twins $(P=0.035)$. Avoiding calories was more common among the active than inactive co-twins $(P=0 \cdot 034)$. Based on food diaries the physically active co-twins had daily energy intake on average $15.5 \mathrm{~kJ} / \mathrm{kg}$ higher than their inactive co-twins $(P=0 \cdot 030)$. The active co-twins also had a higher intake of vitamin $\mathrm{C}(P=0 \cdot 004)$, total water $(P=0 \cdot 044)$, legumes and nuts $(P=0 \cdot 015)$ and sweets $(P=0 \cdot 036)$, as well as a lower energy-adjusted intake of meat $(P=0 \cdot 013)$.

Conclusions: The physically active persons seem to eat more but not necessarily healthier food. However, habitual physical activity may help in eating according to need and in reaching and maintaining a healthy body composition. Therefore, it is necessary to incorporate both dietary and physical activity advice into health counselling.
\end{abstract}

Several chronic diseases, such as obesity, type 2 diabetes mellitus and CVD, along with their underlying mechanisms, can be influenced both by nutrition ${ }^{(1-3)}$ and physical activity ${ }^{(4,5)}$. The WHO Global Strategy on Diet, Physical Activity and Health ${ }^{(6)}$ recommends promoting healthy nutrition along with physical activity, and several nutrition recommendations have also included physical activity ${ }^{(7,8)}$.

According to previous studies physical activity may contribute to the maintenance of a healthy diet. It has been suggested that physical activity could be a possible gateway behaviour for healthier eating ${ }^{(9,10)}$. Earlier studies have shown that those who are physically active consume more vegetables and fruits ${ }^{(11-13)}$, have a lower intake of fat ${ }^{(11,12,14)}$ and a higher intake of fibre ${ }^{(11,12)}$. If a physically active lifestyle modifies eating habits, or if these two lifestyle behaviours interact positively, this knowledge can be used in planning health promotion and in health counselling. However, not all studies have found positive and synergistic associations between physical activity and healthy dietary behaviours ${ }^{(15,16)}$. Thus further studies are needed to determine the nature of the relationship between a physically active lifestyle and eating behaviours.

Previous data on the associations between physical activity and diet are limited to cross-sectional studies ${ }^{(9-14)}$ and exercise trials ${ }^{(15,16)}$, neither of which allow control for possible selection bias due to genetic factors or childhood experiences. By studying monozygotic (MZ) and dizygotic (DZ) twin pairs in the present study, we controlled 
for childhood family environment and partially for genes, as MZ co-twins share all and DZ co-twins share half of their segregating genes. Our design also allows assessment of the true long-term impacts of physical activity, as we selected middle-aged twin pairs discordant for physical activity for almost their entire adult life, i.e. at least 30 years. Thus the purpose of our study was to determine the association between physical activity/inactivity and eating behaviours in twin pairs discordant for physical activity during most of their adult life.

\section{Experimental methods}

\section{Participants}

The present study forms part of the TWINACTIVE study, a wide-ranging investigation into the effects of physical activity and genes on health ${ }^{(17)}$. The participants were recruited from the Finnish Twin Cohort, which comprises same-sex twin pairs born in Finland before 1958 and with both co-twins alive in $1975^{(18)}$. Discordance for physical activity was initially identified in an assessment conducted in 1975, and was based on series of questions on leisure-time physical activity and physical activity during journeys to and from work. The questionnaire included three structured questions; average duration of one session of activity with five response alternatives, monthly frequency of activity with six response alternatives and intensity of activity based on the following question: 'Is your physical activity during leisure time about as strenuous on average as: (i) walking, (ii) alternately walking and jogging, (iii) jogging, (iv) running?' A leisure-time MET (metabolic equivalent) index was calculated by assigning a multiple of the resting metabolic rate (intensity $\times$ duration $X$ frequency) and expressed as a sum score of leisure-time MET hours per day ${ }^{(17,19)}$. In the first stage of the physical activity follow-up in 1981, the discordance found in 1975 continued in 165 pairs out of 5663 healthy pairs. In the second stage, a retrospective follow-up interview on leisure activity from 1980 to 2005 was conducted at 5 -year intervals ${ }^{(19)}$. Fifty-four twin pairs were also discordant at least at four of the six follow-up time points. Finally, sixteen twin pairs (seven MZ and nine DZ pairs; eleven male and five female pairs), who were discordant during most of the 32-year follow-up, fulfilled all our study inclusion criteria and volunteered to participate in the study in 2007 . When the study subjects attended the clinical examinations of the TWINACTIVE study in 2007 , a detailed interview concerning leisuretime physical activity during the previous 12 months was conducted $^{(17)}$. During the follow-up period, from 1980 to 2007 , the inactive co-twins were on average $8 \cdot 8$ MET hours per day less active than their active co-twins $(P<0 \cdot 001)$.

The characteristics of the study subjects by discordance in physical activity are described in Table 1 . There was no statistically significant difference in smoking habits, work status or work-related physical activity between inactive and active co-twins. On average the inactive twins

Table 1 Characteristics of the study subjects by discordance in physical activity ${ }^{(17)}$ : same-sex twin pairs selected from the Finnish Twin Cohort, 2007

\begin{tabular}{|c|c|c|c|c|c|}
\hline Characteristic & & & & & $P$ value for difference \\
\hline \multirow[t]{2}{*}{ Age (years), mean (range) } & \multicolumn{4}{|c|}{$60(50-74)$} & \\
\hline & Mean & SD & Mean & SD & \\
\hline LTPA MET index 1980-2007* & $2 \cdot 2$ & $2 \cdot 3$ & $11 \cdot 0$ & $4 \cdot 1$ & $<0.001$ \\
\hline Height $(\mathrm{cm})$ & $171 \cdot 8$ & $10 \cdot 4$ & $171 \cdot 1$ & $9 \cdot 9$ & 0.63 \\
\hline Weight (kg) & $79 \cdot 5$ & $18 \cdot 4$ & $72 \cdot 9$ & $11 \cdot 9$ & $0 \cdot 12$ \\
\hline $\operatorname{BMI}\left(\mathrm{kg} / \mathrm{m}^{2}\right)$ & $26 \cdot 7$ & $3 \cdot 5$ & $24 \cdot 8$ & $2 \cdot 6$ & 0.09 \\
\hline Fat percentaget (\%) & $27 \cdot 0$ & $5 \cdot 3$ & $21 \cdot 5$ & $6 \cdot 4$ & 0.004 \\
\hline \multirow[t]{2}{*}{ Waist circumference $(\mathrm{cm})$} & $96 \cdot 9$ & $13 \cdot 1$ & $90 \cdot 6$ & $9 \cdot 3$ & 0.059 \\
\hline & $n$ & $\%$ & $n$ & $\%$ & \\
\hline \multicolumn{5}{|l|}{ Smoking } & 0.26 \\
\hline Current smoker & 3 & $18 \cdot 75$ & - & & \\
\hline Quitter & 7 & $43 \cdot 75$ & 8 & $50 \cdot 00$ & \\
\hline Never smoked & 6 & $37 \cdot 50$ & 8 & $50 \cdot 00$ & \\
\hline \multicolumn{5}{|l|}{ Work status } & $0 \cdot 36$ \\
\hline Employed & 9 & $56 \cdot 25$ & 9 & $56 \cdot 25$ & \\
\hline Retired & 5 & $31 \cdot 25$ & 5 & $31 \cdot 25$ & \\
\hline Unemployed & - & & 1 & $6 \cdot 25$ & \\
\hline Other & 2 & $12 \cdot 50$ & 1 & $6 \cdot 25$ & \\
\hline \multicolumn{5}{|l|}{ Work-related physical activity } & $0 \cdot 17$ \\
\hline Sedentary & 3 & $18 \cdot 75$ & 5 & $31 \cdot 25$ & \\
\hline Standing or walking at work & 1 & $6 \cdot 25$ & 3 & $18 \cdot 75$ & \\
\hline Light manual labour & 5 & $31 \cdot 25$ & - & & \\
\hline Heavy manual labour & - & & 1 & $6 \cdot 25$ & \\
\hline
\end{tabular}

LTPA, leisure-time physical activity; MET, metabolic equivalent.

*Physical activity during leisure time and journeys to and from work.

tMeasured using a bioimpedance method (InBody 720; Biospace, Seoul, Korea). 
weighed $6.5 \mathrm{~kg}$ more $(P=0 \cdot 12)$ and had $5 \cdot 5$ percentage units more body fat $(P=0 \cdot 004)$ than their active co-twins. Body fat percentage was assessed after an overnight fast using an InBody 720 (Biospace, Seoul, Korea) eight-point tactile electrode multi-frequency impedance plethysmograph body composition analyser ${ }^{(17)}$. All participants followed a normal diet, except for one active and one inactive individual, who were lactose-intolerant.

The TWINACTIVE study was approved by the Ethics Committee of the Central Hospital of Central Finland. All the participants gave their written informed consent prior to the measurements.

\section{Data collection}

The data were collected with a questionnaire on eating habits and a $5 \mathrm{~d}$ food diary. Dietary habits and attitudes to eating were studied by specific questions drawn from earlier studies ${ }^{(18,20-23)}$. The questionnaire on eating habits comprised questions and statements, with response options, related to restrictive/overeating, health-conscious eating, snacking and psychological aspects of eating (emotional or external eating; see Table 2 below) ${ }^{(20)}$. The food diary was used to measure food consumption and calculate nutrient intake. All of the questionnaire items were chosen for the specific purpose of obtaining information about nutrition, especially in relation to risk for CVD, diabetes mellitus and metabolic syndrome ${ }^{(1)}$.

The eating habits questionnaire and the food diary were mailed to the study participants. They were asked to answer the eating habits questionnaire on the basis of their general eating habits. The food diary was to be filled in during five days within one week (three weekdays and weekend). Detailed written instructions including an example of how to record food consumption were given. During the five

Table 2 Differences in eating habits between inactive $(n 16)$ and active $(n 16)$ co-twins ${ }^{*}$ : same-sex twin pairs selected from the Finnish Twin Cohort, 2007

\begin{tabular}{|c|c|c|c|c|c|}
\hline \multirow[b]{2}{*}{ Statement } & \multicolumn{2}{|c|}{ Inactive } & \multicolumn{2}{|c|}{ Active } & \multirow{2}{*}{$\begin{array}{l}P \text { value for } \\
\text { difference }\end{array}$} \\
\hline & $n$ & $\%$ & $n$ & $\%$ & \\
\hline \multicolumn{6}{|l|}{ Restrictive/overeating } \\
\hline Which of the following best describes you? & & & & & 0.035 \\
\hline It is easy for me to eat about the amount I need to & 7 & $43 \cdot 75$ & 14 & $87 \cdot 50$ & \\
\hline $\begin{array}{l}\text { I quite often eat more than I actually need/I often try to restrict my } \\
\text { eating/At times, I'm on a strict diet, at others I overeat }\end{array}$ & 9 & $56 \cdot 25$ & 2 & $12 \cdot 50$ & \\
\hline \multicolumn{6}{|l|}{ Health-conscious eating } \\
\hline I attempt to maintain healthy eating patterns & & & & & 0.083 \\
\hline Usually/often & 13 & $81 \cdot 25$ & 16 & $100 \cdot 00$ & \\
\hline Sometimes/rarely & 3 & $18 \cdot 75$ & - & & \\
\hline I avoid fatty foods & & & & & $0 \cdot 10$ \\
\hline Usually/often & 10 & $62 \cdot 50$ & 14 & $87 \cdot 50$ & \\
\hline Sometimes/rarely & 6 & $37 \cdot 50$ & 2 & $12 \cdot 50$ & \\
\hline I avoid calories & & & & & 0.034 \\
\hline Usually/often & 3 & $18 \cdot 75$ & 9 & $56 \cdot 25$ & \\
\hline Sometimes/rarely & 13 & $81 \cdot 25$ & 7 & $43 \cdot 75$ & \\
\hline \multicolumn{6}{|l|}{ Snacking } \\
\hline During meal times I eat sufficiently - I don't need to snack between meals & & & & & $0 \cdot 18$ \\
\hline Usually/often & 11 & $68 \cdot 75$ & 14 & $87 \cdot 50$ & \\
\hline Sometimes/rarely & 5 & $31 \cdot 25$ & 2 & $12 \cdot 50$ & \\
\hline My meals are often replaced by snacks & & & & & $0 \cdot 32$ \\
\hline Usually/often & - & & 1 & $6 \cdot 25$ & \\
\hline Sometimes/rarely & 16 & $100 \cdot 00$ & 15 & $93 \cdot 75$ & \\
\hline My food consumption is highest in the evening & & & & & $0 \cdot 32$ \\
\hline Usually/often & 4 & $25 \cdot 00$ & 2 & $12 \cdot 50$ & \\
\hline Sometimes/rarely & 10 & $62 \cdot 50$ & 12 & $75 \cdot 00$ & \\
\hline I graze throughout the evening & & & & & $1 \cdot 0$ \\
\hline Usually/often & 1 & $6 \cdot 25$ & 1 & $6 \cdot 25$ & \\
\hline Sometimes/rarely & 15 & $93 \cdot 75$ & 15 & $93 \cdot 75$ & \\
\hline While I am eating I watch television, etc. & & & & & $0 \cdot 16$ \\
\hline Usually/often & 3 & $18 \cdot 75$ & 1 & $6 \cdot 25$ & \\
\hline Sometimes/rarely & 13 & $81 \cdot 25$ & 15 & $93 \cdot 75$ & \\
\hline \multicolumn{6}{|l|}{ Psychological aspects of eating } \\
\hline I reward myself with good food & & & & & $0 \cdot 32$ \\
\hline Usually/often & 1 & $6 \cdot 25$ & - & & \\
\hline Sometimes/rarely & 15 & $93 \cdot 75$ & 16 & $100 \cdot 00$ & \\
\hline I console myself by eating or drinking & & & & & $0 \cdot 32$ \\
\hline Usually/often & - & & 1 & $6 \cdot 25$ & \\
\hline Sometimes/rarely & 16 & $100 \cdot 00$ & 15 & $93 \cdot 75$ & \\
\hline My eating is triggered by seeing food, food advertisements, etc. & & & & & $1 \cdot 0$ \\
\hline Usually/often & - & & - & & \\
\hline Sometimes/rarely & 16 & $100 \cdot 00$ & 16 & $100 \cdot 00$ & \\
\hline
\end{tabular}

${ }^{*}$ Grouping of statements is drawn from Keski-Rahkonen et al. ${ }^{(20)}$. 
diary days, the study subjects were requested to record in detail all foods and drinks they consumed, using ordinary household measures, and including the time and the place of eating, type of meal, cooking method and type and brands of foods and drinks. The participants returned the completed questionnaires and food diaries when they attended the clinical examinations of the TWINACTIVE study. The food diary was checked by one of the authors (T.L.) when the study subjects personally returned it. When necessary some correction and additions, for example concerning the brands of foods and drinks and size of portions, were done.

For the analysis the response options of the eating habits questionnaire were dichotomized (see Table 2$)^{(20)}$. Food and nutrient intake was calculated from the food diary data by using the Micro-Nutrica software version 2.5 developed and maintained by the Social Insurance Institution of Finland. To analyse food and nutrient intake, the consumption of cereals, vegetables, fruits and berries, fats, milk products, meat, beverages, sugar and sweets were calculated. Food and nutrient intake was calculated in grams per day and adjusted by energy (g/MJ) or percentage of energy (E\%). Micro-Nutrica was updated to include the latest brands of foodstuffs. Nutrient losses during cooking and the possible use of vitamin and mineral supplements were not included in the calculations.

\section{Statistical analysis}

All statistical analyses were based on pairwise tests comparing the inactive members of twin pairs with their active co-twins. Analyses of categorical variables were carried out with the Symmetry test (Stata). The ShapiroWilk test was used to test the normality of continuous variables. The two-sided paired-sample $t$ test was used for normally distributed data. Non-normally distributed data were analysed with the Wilcoxon signed rank test. In all analyses the level of significance was set at $P<0 \cdot 05$, and we defined a tendency to differences as $0 \cdot 05<P<0 \cdot 10$. The data were analysed using the SPSS version $15 \cdot 0$ (SPSS Inc., Chicago, IL, USA) and Stata version $8 \cdot 0$ (StataCorp LP, College Station, TX, USA) statistical software packages.

In our data the statistical power for detecting significant $(P<0.05)$ difference between co-twins was 0.90 for vitamin $C$ intake and 0.64 for energy intake per body weight. So, it should be noted that for detecting differences smaller than $20 \%$ between the co-twins there was a risk for type 2 error in the case where standard deviations were high.

\section{Results}

Results of the eating habits questionnaire are summarised in Table 2. The physically active co-twins more often reported that it is easy to eat according to need, whereas overeating and/or restrictive eating was more common among the inactive co-twins $(P=0 \cdot 035)$. Avoiding calories was significantly more common in the active than inactive co-twins $(P=0 \cdot 034)$, and attempting to maintain healthy eating patterns tended to be more common among the active $(P=0 \cdot 083)$, as did avoiding fatty foods $(P=0 \cdot 10)$. The questions related to snacking or the psychological aspects of eating did not differ significantly between the co-twins.

The differences between the inactive and active cotwins in food consumption and nutrient intakes are shown in Tables 3 and 4 . The physically active members of twin pairs had a higher mean daily energy intake per body weight than their inactive co-twins (97-4 (SD 24.8) $v$. $81.9(\mathrm{sD} 15 \cdot 3) \mathrm{kJ} / \mathrm{kg}, P=0 \cdot 030$ ). The total daily mean energy intake was non-significantly higher among the active twins (7·1 (sD 1.9) v. $6 \cdot 4(\mathrm{sD} 1 \cdot 5) \mathrm{MJ} / \mathrm{d}, P=0 \cdot 20)$. The physically active as compared with the inactive cotwins had higher total daily intake of water (2114 (SD 568) v. $1720(\mathrm{sD} 571) \mathrm{g} / \mathrm{d}, P=0 \cdot 044)$ and vitamin C (91.7 (sD 34.8)

Table 3 Differences in food consumption between inactive and active co-twins: same-sex twin pairs selected from the Finnish Twin Cohort, 2007

\begin{tabular}{|c|c|c|c|c|c|c|c|}
\hline \multirow[b]{2}{*}{ Food } & \multicolumn{2}{|c|}{ Inactive $(n 16)$} & \multicolumn{2}{|c|}{ Active $(n 16)$} & \multirow[b]{2}{*}{ Mean difference } & \multirow[b]{2}{*}{$95 \% \mathrm{Cl}$} & \multirow[b]{2}{*}{$P$ value for difference } \\
\hline & Mean & SD & Mean & SD & & & \\
\hline All beverages $(\mathrm{g} / \mathrm{d})^{\star}$ & 1152 & 477 & 1469 & 566 & -318 & $-656,21$ & $0 \cdot 13$ \\
\hline Whole fruit juice $(\mathrm{g} / \mathrm{d})^{\star}$ & 7 & 21 & 26 & 40 & -19 & $-45,8$ & $0 \cdot 16$ \\
\hline Milk $(g / d)^{\star}$ & 171 & 149 & 197 & 164 & -26 & $-133,81$ & $0 \cdot 84$ \\
\hline Coffee $(\mathrm{g} / \mathrm{d})$ & 367 & 206 & 367 & 230 & $0 \cdot 1$ & $-190,190$ & $1 \cdot 0$ \\
\hline Tea $(g / d)^{*}$ & 28 & 41 & 32 & 57 & -4 & $-39,31$ & $0 \cdot 76$ \\
\hline Alcoholic drinks $(\mathrm{g} / \mathrm{d})^{*}$ & 122 & 251 & 147 & 183 & -24 & $-126,77$ & 0.55 \\
\hline Other beverages $(g / d)^{\star}, t$ & 457 & 356 & 702 & 634 & -245 & $-495,5$ & 0.044 \\
\hline Vegetables, fruits and berries $(\mathrm{g} / \mathrm{d})^{\star}$ & 371 & 134 & 408 & 135 & -37 & $-126,52$ & $0 \cdot 30$ \\
\hline Fruits and berries $(\mathrm{g} / \mathrm{d})$ & 144 & 78 & 171 & 88 & -27 & $-70,16$ & $0 \cdot 20$ \\
\hline Potatoes $(\mathrm{g} / \mathrm{d})^{*}$ & 98 & 63 & 78 & 57 & 20 & $-25,65$ & $0 \cdot 41$ \\
\hline Legumes and nuts $(\mathrm{g} / \mathrm{d})^{\star}$ & 7 & 14 & 20 & 30 & -13 & $-27,2$ & 0.015 \\
\hline Fruits, berries and whole fruit juice $(\mathrm{g} / \mathrm{d})$ & 151 & 87 & 197 & 94 & -46 & $-89,-2$ & 0.040 \\
\hline Wholegrain bread (g/d) & 105 & 56 & 102 & 35 & 3 & $-33,38$ & $0 \cdot 87$ \\
\hline
\end{tabular}

*Non-normally distributed variables.

tSoft drinks, water, etc. (excluding whole fruit juice, milk, coffee, tea and alcoholic drinks). 
Table 4 Differences in nutrient intake between inactive and active co-twins: same-sex twin pairs selected from the Finnish Twin Cohort, 2007

\begin{tabular}{|c|c|c|c|c|c|c|c|c|}
\hline \multirow[b]{2}{*}{ Nutrient } & & \multicolumn{2}{|c|}{ Inactive ( $n$ 16) } & \multicolumn{2}{|c|}{ Active $(n 16)$} & \multirow[b]{2}{*}{ Mean difference } & \multirow[b]{2}{*}{$95 \% \mathrm{Cl}$} & \multirow[b]{2}{*}{$P$ value for difference } \\
\hline & & Mean & SD & Mean & SD & & & \\
\hline \multirow[t]{2}{*}{ Energy } & $\mathrm{MJ} / \mathrm{d}$ & $6 \cdot 4$ & $1 \cdot 5$ & $7 \cdot 1$ & $1 \cdot 9$ & -0.6 & $-1 \cdot 6,0 \cdot 4$ & $0 \cdot 20$ \\
\hline & $\mathrm{kcal} / \mathrm{d}$ & 1539 & 357 & 1685 & 452 & 147 & $-382,88$ & $0 \cdot 20$ \\
\hline \multirow[t]{2}{*}{ Energy per body weight } & $\mathrm{kJ} / \mathrm{kg}^{*}$ & $81 \cdot 9$ & $15 \cdot 3$ & $97 \cdot 4$ & $24 \cdot 8$ & $-15 \cdot 5$ & $-28 \cdot 8,-2 \cdot 1$ & 0.030 \\
\hline & $\mathrm{kcal} / \mathrm{kg}^{*}$ & $19 \cdot 6$ & $3 \cdot 7$ & $23 \cdot 3$ & $5 \cdot 9$ & $-3 \cdot 7$ & $-6.9,-0.5$ & 0.030 \\
\hline \multirow[t]{2}{*}{ Protein } & $E \%$ & $18 \cdot 1$ & 1.9 & $17 \cdot 5$ & $2 \cdot 3$ & $0 \cdot 7$ & $-0 \cdot 8,2 \cdot 1$ & $0 \cdot 36$ \\
\hline & $\mathrm{g} / \mathrm{d}$ & $68 \cdot 4$ & $17 \cdot 2$ & $72 \cdot 0$ & $19 \cdot 7$ & $-3 \cdot 6$ & $-16 \cdot 1,8 \cdot 8$ & 0.54 \\
\hline \multirow[t]{2}{*}{ Carbohydrate } & E\% & $45 \cdot 2$ & $6 \cdot 0$ & $46 \cdot 7$ & $6 \cdot 8$ & $-1 \cdot 5$ & $-6 \cdot 0,3 \cdot 0$ & 0.48 \\
\hline & $\mathrm{g} / \mathrm{d}$ & 169 & 34 & 192 & 53 & -23 & $-54,8$ & $0 \cdot 14$ \\
\hline \multirow[t]{2}{*}{ Fat } & $\mathrm{E} \%$ & $33 \cdot 6$ & $6 \cdot 2$ & $31 \cdot 7$ & $6 \cdot 2$ & 1.9 & $-2 \cdot 6,6 \cdot 5$ & 0.38 \\
\hline & $g / d$ & $57 \cdot 9$ & $20 \cdot 8$ & $59 \cdot 6$ & $21 \cdot 8$ & $-1 \cdot 7$ & $-12 \cdot 9,9 \cdot 5$ & $0 \cdot 75$ \\
\hline \multirow[t]{2}{*}{ Saturated fat } & $\mathrm{E} \%$ & $12 \cdot 5$ & 3.2 & $11 \cdot 4$ & $2 \cdot 9$ & $1 \cdot 1$ & $-1 \cdot 6,3 \cdot 7$ & $0 \cdot 40$ \\
\hline & $g / d$ & $21 \cdot 5$ & $8 \cdot 5$ & $21 \cdot 2$ & $7 \cdot 7$ & $0 \cdot 2$ & $-4 \cdot 5,5 \cdot 0$ & 0.92 \\
\hline \multirow[t]{2}{*}{ Monounsaturated fat } & $\mathrm{E} \%$ & $11 \cdot 6$ & $2 \cdot 4$ & $11 \cdot 1$ & $3 \cdot 1$ & $0 . \overline{5}$ & $-1 \cdot 3,2 \cdot 4$ & 0.56 \\
\hline & $g / d^{*}$ & $20 \cdot 1$ & $7 \cdot 7$ & $21 \cdot 0$ & $9 \cdot 9$ & -0.9 & $-6 \cdot 0,4 \cdot 2$ & $0 \cdot 74$ \\
\hline \multirow[t]{2}{*}{ Polyunsaturated fat } & E\%* & $6 \cdot 0$ & $1 \cdot 3$ & $6 \cdot 0$ & $1 \cdot 6$ & $0 \cdot 1$ & $-1 \cdot 1,1 \cdot 2$ & 0.64 \\
\hline & $\mathrm{g} / \mathrm{d}^{*}$ & $10 \cdot 4$ & $4 \cdot 0$ & $11 \cdot 3$ & $4 \cdot 8$ & -0.9 & $-3 \cdot 8,2 \cdot 1$ & 0.68 \\
\hline \multirow[t]{2}{*}{ Cholesterol } & $\mathrm{mg} / \mathrm{d}$ & 214 & 86 & 196 & 84 & 18 & $-39,75$ & 0.51 \\
\hline & $\mathrm{mg} / \mathrm{MJ}$ & $32 \cdot 6$ & $7 \cdot 6$ & $27 \cdot 8$ & $9 \cdot 1$ & $4 \cdot 8$ & $-1 \cdot 8,11 \cdot 3$ & $0 \cdot 14$ \\
\hline \multirow[t]{2}{*}{ Dietary fibre } & $\mathrm{g} / \mathrm{d}$ & $19 \cdot 8$ & $5 \cdot 4$ & $21 \cdot 6$ & $6 \cdot 1$ & $-1 \cdot 8$ & $-5 \cdot 5,1 \cdot 9$ & 0.31 \\
\hline & $\mathrm{g} / \mathrm{MJ}^{*}$ & $3 \cdot 2$ & 0.9 & 3.2 & 0.9 & 0.001 & $-0.5,0.5$ & 0.92 \\
\hline \multirow{2}{*}{ Vitamin C } & $\mathrm{mg} / \mathrm{d}$ & $69 \cdot 7$ & $31 \cdot 8$ & $91 \cdot 7$ & $34 \cdot 8$ & $-22 \cdot 0$ & $-35 \cdot 6,-8 \cdot 4$ & 0.004 \\
\hline & $\mathrm{g} / \mathrm{MJ}^{*}$ & $10 \cdot 9$ & 4.9 & $13 \cdot 9$ & $6 \cdot 2$ & $-3 \cdot 0$ & $-6 \cdot 3,0 \cdot 4$ & 0.07 \\
\hline \multirow[t]{2}{*}{$\mathrm{Na}$} & $\mathrm{mg} / \mathrm{d}$ & 2846 & 878 & 2706 & 798 & 141 & $-360,641$ & 0.56 \\
\hline & $\mathrm{mg} / \mathrm{MJ}$ & 443 & 77 & 390 & 85 & 52 & $-1,105$ & 0.053 \\
\hline \multirow[t]{2}{*}{$\mathrm{K}$} & $\mathrm{g} / \mathrm{d}$ & 3026 & 694 & 3322 & 882 & -297 & $-924,331$ & 0.33 \\
\hline & $\mathrm{mg} / \mathrm{MJ}$ & 479 & 91 & 482 & 96 & -3 & $-79,74$ & 0.95 \\
\hline \multirow[t]{2}{*}{$\mathrm{Mg}$} & $\mathrm{mg} / \mathrm{d}$ & 313 & 80 & 355 & 98 & -41 & $-116,33$ & $0 \cdot 26$ \\
\hline & $\mathrm{mg} / \mathrm{MJ}$ & $49 \cdot 5$ & $11 \cdot 3$ & $51 \cdot 0$ & 8.9 & $-1 \cdot 5$ & $-10 \cdot 3,7 \cdot 2$ & 0.72 \\
\hline \multirow[t]{2}{*}{ Folate } & $\mu \mathrm{g} / \mathrm{d}$ & 236 & 57 & 256 & 53 & -20 & $-56,17$ & $0 \cdot 27$ \\
\hline & $\mu \mathrm{g} / \mathrm{MJ}^{*}$ & $37 \cdot 1$ & $7 \cdot 5$ & $37 \cdot 5$ & $7 \cdot 7$ & -0.4 & $-5 \cdot 4,4 \cdot 7$ & 0.88 \\
\hline \multirow[t]{2}{*}{ Ethanol } & $E \% *$ & $3 \cdot 1$ & $5 \cdot 2$ & $4 \cdot 1$ & $4 \cdot 9$ & $-1 \cdot 0$ & $-2 \cdot 9,0.9$ & $0 \cdot 40$ \\
\hline & $\mathrm{g} / \mathrm{d}^{*}$ & $6 \cdot 8$ & $11 \cdot 3$ & $9 \cdot 9$ & $12 \cdot 7$ & $-3 \cdot 2$ & $-8 \cdot 1,1 \cdot 8$ & 0.36 \\
\hline \multirow{2}{*}{ Water } & $\mathrm{g} / \mathrm{d}^{*}$ & 1720 & 571 & 2114 & 568 & -394 & $-748,-41$ & 0.044 \\
\hline & $\mathrm{g} / \mathrm{MJ}^{*}$ & 273 & 89 & 309 & 76 & -35 & $-77,6$ & 0.13 \\
\hline
\end{tabular}

$\mathrm{E} \%$, percentage of energy.

${ }^{*}$ Non-normally distributed variables.

v. $69 \cdot 7$ (sD 31.8) $\mathrm{mg} / \mathrm{d}, P=0.004)$ and they tended to receive less $\mathrm{Na}$ (energy-adjusted intake: 390 (SD 85) $v .443$ (sD 77) $\mathrm{mg} / \mathrm{MJ}, P=0 \cdot 053$ ). The active co-twins also consumed more legumes and nuts (20 (SD 30) $v .7$ (SD 14) g/d, $P=0.015)$ and sweets (6 (SD 10) v. 1 (sD 3) $\mathrm{g} / \mathrm{d}$, $P=0 \cdot 036$ ), but ate less meat (energy-adjusted intake: 14 (SD 6) v. 20 (SD 8) g/MJ, $P=0 \cdot 013$ ). Combined fruit, berry and whole fruit juice consumption differed significantly between the active and inactive co-twins (197 (SD 94) $v$. 151 (sD 87) g/d, $P=0 \cdot 040)$.

\section{Discussion}

Our results showed that the physically active co-twins were better able to eat according to need than their inactive co-twins. Moreover, a health-conscious eating style tended to be more common among the active than among the inactive co-twins. In spite of that, habitual physical activity had a stronger influence on the quantity than quality of food.

We found that the physically active members of twin pairs had a higher daily energy intake per body weight than their inactive co-twins. In earlier studies physically active individuals have usually had higher energy intake $^{(24,25)}$. Despite the higher energy intake per body weight, an earlier analysis of these same twin pairs indicated that the active co-twins had significantly lower body fat percentage than their inactive co-twins $(21.5 \% v$. $27 \cdot 0 \%)^{(26)}$. This indicates that lack of physical activity, and thus presumably lower energy expenditure, contributed to the higher body fat percentage of the inactive co-twins. Hence, regular exercise is useful for both improving body composition and allowing leeway with respect to eating and energy intake. However, it is important that with increased energy need/intake, attention is paid to food quality. Our study demonstrates that the relationship between physical activity level, food intake and body weight $v$. body fat is complex, and if not adequately taken into account can lead to spurious conclusions.

It is noteworthy that although caloric avoidance was more common among the active co-twins, they more frequently reported it being easy to eat according to need, while overeating and/or restrictive eating was more common among the inactive co-twins. An easiness to eat according to need may indicate an improved sensitivity to 
match sensations of hunger to physiological requirements. Thus it may be easier for active individuals to match energy intake to energy expenditure, and accordingly to maintain an adequate body composition ${ }^{(27)}$. Other aspects of eating habits, such as snacking or emotional or external eating, did not differ significantly between the active and inactive co-twins.

As expected, the average total daily intake of water was higher among physically active than inactive co-twins. Little attention has been paid to whether good hydration has effects on health ${ }^{(28)}$.

We did not find strong support for earlier findings that physically active subjects eat more fruits and vegetables $^{(11-13)}$, have a higher intake of fibre ${ }^{(11,12)}$ or lower intake of $\mathrm{fat}^{(11,12,14)}$. However, we found that intake of vitamin $\mathrm{C}$ was higher among the active than inactive cotwins, which is in line with some previous studies ${ }^{(11,12)}$. Greater intake of vitamin $\mathrm{C}$ might be explained by the active twins' greater consumption of fruits, berries and whole fruit juice combined. Higher intake of legumes and nuts and lower energy-adjusted intake of meat and Na may slightly be related to the trend towards a health-conscious eating style found among the active co-twins. Eating more sweets by active co-twins indicates that an active lifestyle does not exclusively result in better eating habits, but that exercise allows more flexibility to food choices without unfavourable health effects, such as weight gain. However, the difference in sweets between the active and inactive cotwins may partly be explained by under-reporting of sweet foods among inactive co-twins ${ }^{(29)}$.

Thus, although some previous studies have suggested that physical activity and eating habits are correlated behaviours $^{(11)}$ or that physical activity could be a possible gateway behaviour for healthier eating habits ${ }^{(9,10)}$, our twin study does not provide strong support for these ideas. This agrees with some previous findings ${ }^{(15,16,30)}$. According to our results physical activity may be beneficial in eating according to need, but as shown in earlier exercise trials in sedentary women, spontaneous enhancement in quality of diet along with increasing physical activity cannot always be expected ${ }^{(15,30)}$.

Because there were more similarities than differences in the co-twins' eating behaviours (see Tables 3 and 4), it seems that genes may have an effect on eating behaviours as proposed earlier ${ }^{(31)}$. However, as twin pairs have a shared childhood family environment and the lifestyles of co-twins usually show greater similarity than those of other individuals, it seems that the differences in physical activity and dietary habits observed in the present study may have a causal relationship.

Among co-twins discordance in physical activity over a very long period is the major strength of the present study. Our twin study design allowed control for childhood environment. Because the study sample was small, analysis was conducted for MZ and DZ twins together, from which follows that genes could be partially, but not completely, controlled for. Moreover, males and females were pooled, again because of the small sample. A further limitation of the study was the cross-sectional nature of the nutrition data. Prospective data on eating habits were not available and retrospective nutrition data collection would have been difficult to gather reliably for such a long period. Because the statistical power of the study was low as only sixteen twin pairs were involved, the possibility of type 2 error exists (false negatives).

Self-reported dietary data are often influenced by reporting biases such as under-reporting ${ }^{(32)}$; for example, overweight subjects have been shown to under-report more than leaner ones ${ }^{(33)}$, even within twin pairs ${ }^{(29)}$. We sought to minimize errors by using commonly used data collection methods. We gave participants detailed written instructions and an example showing how to complete the food diary, and the analysis of the food diary data was done in part with energy-adjusted outcomes. Our $5 \mathrm{~d}$ food diary, the three weekdays and the weekend, tends slightly to emphasize the weekend, and possibly insufficient motivation remained during the last recording days to record all drinks and foods with the requisite precision. Total energy intake was relatively low in both twin groups, which may indicate under-reporting. This should be taken into account when interpreting our results. It should also be noted that our eating habits questionnaire was based on totally subjective measures.

\section{Conclusion}

Our results showed that physically active co-twins ate more but not necessarily healthier foods and still remained leaner than their inactive counterparts. Habitual physical activity may help in eating according to need and in reaching and maintaining a healthy body weight and composition. Therefore it is necessary to include both dietary and physical activity advice in health counselling which aims at behavioural change towards a healthier lifestyle.

\section{Acknowledgements}

Sources of funding: The TWINACTIVE study was supported by the Academy of Finland (Grant 114866 and Centre of Excellence in Complex Disease Genetics) and the Finnish Ministry of Education. U.M.K. was supported by the Juho Vainio Foundation, T.L. was supported by the Finnish Cultural Foundation, and K.H.P. was supported by the Jalmari and Rauha Ahokkaan säätiö. Conflict of interest: The authors declare no conflict of interest. Autbors' contributions: All authors contributed to the study design; T.L., M.A. and U.M.K. carried out data collection; M.R. and T.L. analysed the nutrition data; M.R. drafted the manuscript. All authors contributed to the interpretation of data and critical revision of the manuscript, and all authors approved the final version of the 
manuscript. Acknowledgments: We thank Professor Aila Rissanen for her work in constructing the questionnaire on eating habits, and MSc Riikka Suutala for her work in coding the food diary data.

\section{References}

1. World Health Organization (2003) Diet, Nutrition and the Prevention of Chronic Diseases. Joint WHO/FAO Expert Consultation. WHO Technical Report Series no. 916. Geneva: WHO.

2. Lindström J, Peltonen M, Eriksson JG et al. (2006) Highfiber, low-fat diet predicts long-term weight loss and decreased type 2 diabetes risk: the Finnish Diabetes Prevention Study. Diabetologia 49, 912-920.

3. Dauchet L, Amouyel P, Hercberg S et al. (2006) Fruit and vegetable consumption and risk of coronary heart disease: a meta-analysis of cohort studies. J Nutr 136, 2588-2593.

4. Kujala UM (2009) Evidence on the effects of exercise therapy in the treatment of chronic disease. BrJ Sports Med 43, 550-555.

5. Physical Activity Guidelines Advisory Committee (2008) Physical Activity Guidelines Advisory Committee Report, 2008. Washington, DC: US Department of Health and Human Services

6. World Health Organization (2004) Global Strategy on Diet, Physical Activity and Health. Geneva: WHO.

7. US Department of Health and Human Services \& US Department of Agriculture (2005) Dietary Guidelines for Americans, 6th ed. Washington, DC: US Government Printing Office.

8. Becker W, Lyhne N, Pedersen AN et al. (2004) Nordic Nutrition Recommendations 2004 - integrating nutrition and physical activity. Scand J Nutr 48, 178-187.

9. Tucker M \& Reicks M (2002) Exercise as a gateway behaviour for healthful eating among older adults: an exploratory study. J Nutr Educ Behav 34, Suppl. 1, S14-S19.

10. Blakely F, Dunnagan T, Haynes G et al. (2004) Moderate physical activity and its relationship to select measures of a healthy diet. J Rural Health 20, 160-165.

11. Gillman MW, Pinto BM, Tennstedt S et al. (2001) Relationships of physical activity with dietary behaviors among adults. Prev Med 32, 295-301.

12. Matthews CE, Hebert JR, Ockene IS et al. (1997) Relationship between leisure-time physical activity and selected dietary variables in the Worcester Area Trial for Counselling in Hyperlipidemia. Med Sci Sports Exerc 29, 1199-1207.

13. Mummery WK, Kolt G, Schofield G et al. (2007) Associations between physical activity and other lifestyle behaviors in older New Zealanders. J Phys Act Health 4, 411-422.

14. Simoes EJ, Byers T, Coates RJ et al. (1995) The association between leisure-time physical activity and dietary fat in American adults. Am J Public Health 85, 240-244.

15. Dutton GR, Napolitano MA, Whiteley JA et al. (2008) Is physical activity a gateway behavior for diet? Findings from a physical activity trial. Prev Med 46, 216-221.
16. Wilcox S, King AC, Castro C et al. (2000) Do changes in physical activity lead to dietary changes in middle and old age? Am J Prev Med 18, 276-283.

17. Leskinen T, Waller K, Mutikainen S et al. (2009) Effects of 32-year leisure time physical activity discordance in twin pairs on health (TWINACTIVE study); aims, design and results for physical fitness. Twin Res Hum Genet 12, 108-117.

18. Kaprio J, Pulkkinen L \& Rose RJ (2002) Genetic and environmental factors in health-related behaviors: studies on Finnish twins and twin families. Twin Res 5, 366-371.

19. Waller K, Kaprio J \& Kujala UM (2008) Associations between long-term physical activity, waist circumference and weight gain: a 30-year longitudinal twin study. Int J Obes (Lond) 32, 353-361.

20. Keski-Rahkonen A, Bulik CM, Pietiläinen KH et al. (2007) Eating styles, overweight and obesity in young adult twins. Eur J Clin Nutr 61, 822-829.

21. Karlsson J, Persson LO, Sjöström L et al. (2000) Psychometric properties and factor structure of the Three-Factor Eating Questionnaire (TFEQ) in obese men and women. Results from the Swedish Obese Subjects (SOS) study. Int J Obes Relat Metab Disord 24, 1715-1725.

22. Roininen K, Lähteenmäki L \& Tuorila H (1999) Quantification of consumer attitudes to health and hedonic characteristics of foods. Appetite 33, 71-88.

23. Willett W (1998) Nutritional Epidemiology. Oxford: Oxford University Press.

24. Blair SN, Ellsworth NM, Haskell WL et al. (1981) Comparison of nutrient intake in middle-aged men and women runners and controls. Med Sci Sports Exerc 13, 310-315.

25. Butterworth DE, Nieman DC, Underwood BC et al. (1994) The relationship between cardiorespiratory fitness, physical activity, and dietary quality. Int J Sport Nutr 4, 289-298.

26. Leskinen T, Sipilä S, Alen M et al. (2009) Leisure-time physical activity and high-risk fat: a longitudinal population-based twin study. Int J Obes (Lond) 33, 1211-1218.

27. Blundell JE \& King NA (1999) Physical activity and regulation of food intake: current evidence. Med Sci Sports Exerc 31, Suppl. 11, S573-S583.

28. Manz F \& Wentz A (2005) The importance of good hydration for the prevention of chronic diseases. Nutr Rev 63, 6 Pt 2, S2-S5.

29. Pietiläinen KH, Korkeila M, Bogl LH et al. (2010) Inaccuracies in food and physical activity diaries of obese subjects: complementary evidence from doubly-labeled water and co-twin assessments. Int J Obes (Lond) 34, 437-445.

30. Butterworth DE, Nieman DC, Perkins R et al. (1993) Exercise training and nutrient intake in elderly women. J Am Diet Assoc 93, 653-657.

31. Keskitalo K, Silventoinen K, Tuorila H et al. (2008) Genetic and environmental contributions to food use patterns of young adult twins. Physiol Behav 93, 235-242.

32. Hirvonen T, Männistö S, Roos E et al. (1997) Increasing prevalence of underreporting does not necessarily distort dietary surveys. Eur J Clin Nutr 51, 297-301.

33. Heitmann BL \& Lissner L (1995) Dietary underreporting by obese individuals - is it specific or non-specific? BMJ 311, 986-989. 